Guichon, N. \& McLornan, S. (2008). "The effects of multimodality on L2 learners: Implications for CALL resource design." To be published in System. Vol. 36, n ${ }^{\circ} 1$.

\title{
The effects of multimodality on L2 learners: implications for CALL resource design
}

Nicolas Guichon ${ }^{1}$, Sinead McLornan ${ }^{2}$

${ }^{1}$ Language Centre - Laboratoire ICAR, Lyon 2 University, 5 avenue Pierre-MendèsFrance 69676 Bron cedex.

2 European Business Institute, 13 Place du Triforium, 38080 L'Isle d'Abeau.

\begin{abstract}
This paper presents results of a pilot study investigating the effects of multimodality upon second language comprehension, with a view to informing future instructional design. An experiment was designed to compare the understanding of an authentic BBC audiovisual recording, which was presented to four groups of French undergraduate students $(\mathrm{N}=40)$. Group 1 was exposed to sound alone, group 2 to image and sound, group 3 to image, sound and L1 subtitles and group 4 to image, sound and L2 subtitles. Students were asked to produce a detailed written summary in English, with the help of their own notes. The results indicate that comprehension improves when learners are exposed to a text in several modalities. In addition, they suggest that L2 subtitling is more beneficial than L1 because it causes less lexical interference.
\end{abstract}

Key words: second language listening, multimodality, comprehension, materials design 


\section{Rationale for research}

Advocates of multimedia learning often emphasise the part played by multimodality within Computer Aided Language Learning (CALL) and suggest that it is strongly supportive of learning (Rost, 2002, p. 105). Multimodality makes sensory information accessible in diverse semiotic codes and offers the opportunity to comprehend information through different channels (Legros and Crinon, 2002). Yet, as Kress and van Leeuwen (1996, p. 76) insist, visual and verbal media "are not simply alternative means of representing the 'same thing'". Multimodality entails not only accessing information in different formats but also establishing interactivity between these representations. Thus, CALL provides learners with several parallel possibilities of developing their comprehension skills- possibilities which they integrate by using their experience of multimodal representation in real-life contexts. But it also enables learners to manipulate the various channels. They can control the flow of information with pause and rewind buttons thus breaking free of the temporal linearity of oral speech; they can choose among or combine several formats (sound, image and text) in order to achieve the same information; they can access titles, subtitles (partial or complete), conceptual maps or online dictionaries to enhance comprehension. This list gives an example of how teaching systems can combine different technological possibilities (e.g. the functions of the video recorder) with a range of media sources and presentation types, all supported by the pedagogical assistance traditionally provided in a classroom context.

Nonetheless, if multimodal teaching systems seem to afford a potential for learning, this potential needs to be carefully assessed against the limitations upon learners' capacity for facing conflicting demands on their cognitive resources. As Schnotz (1999) points out, the successful use of technologies in learning and instruction is dependent on a better "understanding of the interplay between different forms of external representations and the learners' internal mental structures and cognitive processes". In addition, designing a computer-mediated language teaching system involves careful consideration of the type of language (genres, registers) that are provided for the purpose of learning as well as how they are to be presented. Despite the opportunity afforded by CALL of integrating speech, video images, subtitles or translation into any text, relatively few studies have been carried out to date to ascertain the impact of multimodality upon text comprehension and upon subsequent productive output in a foreign language. 


\section{Background}

What are the potentials and limits of presenting the same information in different modalities, e.g. with video and subtitles, for text comprehension?

So far as the merits of using video for comprehension of text, it seems self-evident that the addition of images to sound helps to set the scene of events and above all to provide geographical bearings within a text. In addition, video has an obvious benefit in that it more closely replicates real-life face to face experiences and provides additional sources of information such as speakers' body language or their physical actions (Baltova, 1999). But it also has the disadvantage of imposing additional demands upon attention, making it necessary for the learner to direct attention in a constructive way. Multimodal input presentation may thus either disperse attention especially when there is conflicting information, or it can indeed help to direct attention. Visual stimuli may help to focus an individual's attention on the ongoing discourse representation (Brown and Yule, 1983) in a way that one mode, e.g. exposure to just audio data, might not.

The multimodality principle was verified by a study carried out by Kon (2002), quoted in Chapelle (2003, p. 87), investigating the comprehension of a lecture delivered in different modes. Results based on post-test performance after a significant period of time indicate that the greater the number of presentation modes, the higher the number of new words acquired.

A particular area of interest concerns the role of subtitles. It is now common practice to present subtitled versions of video extracts on the assumption that the combination of both text and images facilitates comprehension. The question is whether subtitles in L1 are equally or more effective than those in L2. Baltova (1999) conducted an experiment with 93 lower-intermediate learners that concluded that a video document in the target language subtitled in the target language, what she termed "bimodal video", was the most beneficial condition for the recall of L2 vocabulary and of content. One might question the use of subtitles in instructional materials from two angles. Firstly, subtitles detract from the ecological validity of video transmission as they are not available in real-life situations. Secondly, one might argue that written information does not support oral information unequivocally, as it is a competitor for the learner's attention rather than a complementary feature. Although subtitling enables learners to check areas of semantic and lexical ambiguity, reading subtitles adds an extra operation to the comprehension task and creates potential interference due to the constraints upon human information processing capacity (Tardieu and Gyselinck, 2003).

Wickens (1984, p. 15) makes two illuminating points about attention. He first compares attention to "the searchlight that chooses information sources to process". Thus, carrying out a complex task that draws on both visual and auditory information sources 
may cause what researchers have called the split-attention effect, that is "the impairment in learning that arises from the need to mentally integrate disparate sources of information" (Moreno and Mayer, 1999). The second metaphor devised by Wickens (ibid.) recognises attention as a "resource of limited availability". In the case of a listening comprehension task, some processes (e.g. recognizing words) might require more of this resource, which might provoke a deterioration in the performance of other processes (e.g. note-taking) that receive less attention. Issues associated with attention should therefore be of prime concern for materials designers in cases where multimedia settings oblige learners to process multiple information sources simultaneously as they carry out complex tasks.

\section{Research design}

Our pilot study concerned the effect of multimodality on an L2 comprehension task and examined the impact of different types of input upon L2 learners' comprehension of spoken English. It sought evidence that might provide some general indications as to:

1. the impact of multimodal presentation on understanding an authentic oral document;

2. the benefits and limitations of image and of L1 and L2 subtitling upon the comprehension of inexperienced L2 listeners;

3. the extent to which the use of L1 or L2 subtitles might interfere with comprehension as measured by learners' written reports.

The number and nature of the available channels of information formed the independent variable. In all, the study featured four conditions:

Modality 1: audio alone

Modality 2: video with audio

Modality 3: video with audio and TL (English) subtitles

Modality 4: video with audio and L1 (French) subtitles

In Modalities 3 and 4, the recording was subtitled in its entirety.

To determine the effects of the variables upon comprehension, we used learners' written productions based upon notes taken while viewing the material.

\section{Participants}

Forty French-speaking students in a French University constituted the informant sample. These 20 year-old non-language specialist students were relatively 
inexperienced L2 listeners. Out of a population of 85 students, we selected four subgroups of 10 students based on the results of in-house ESL placement test. We restricted participants to those with intermediate level scores in order to obtain as homogeneous a sample as possible.

\section{Materials}

The material for this study was a 3-minute BBC news report dealing with a FrancoAmerican couple living in the suburbs of Washington D.C. The couple are both selfemployed hairdressers, have a 3 year-old son and are expecting a second baby very shortly. An au-pair looks after their son. Due to the difficult working conditions for the self-employed, (no paid maternity-leave, for instance), the mother is planning to go back to work just five weeks after the birth. One of our reasons for choosing this report was that it retained its quality in the audio-alone version.

\section{Procedure}

The source material was presented to each group of ten students in a different condition. All tests took place in the morning. The experimental procedure was strictly identical for all four groups and was as follows:

- explanation of test instructions and objectives/goals to students in French

- first exposure to report (note-taking allowed in L1 or L2)

- 4-minute break for silent independent note-review

- second listening/viewing during which further note-taking was allowed in L1 or L2

- 20 minutes for writing as thorough a summary as possible.

The source document was analysed in terms of 35 semantic units (see Appendix 1) which were deemed central to understanding by the researchers. They foregrounded the main characters (French man, three-year-old son), the setting (Washington, exclusive hair salon) and the key arguments (few benefits, only a few hours together). A few superfluous details (e.g. the couple has two dogs, it is Christmas time) were removed from the text base analysis but the main body of the script was represented.

Because our approach aimed at identifying which of the four modalities facilitates comprehension and how students' written productions are influenced by the nature of the task, we chose a written summary rather than the comprehension questions and gapfill test used by Baltova (1999) in a similar study with non-specialist students of French in Canada. This methodology gave us the possibility of comparing the students' roughcopies and their final summary in order to provide information regarding the possible effects of cognitive overload and L1-L2 interference. 
The results (see figure 1 below) were obtained by calculating the number of semantic units from the materials that were reported by students in the written summary. When a student simply wrote a word or phrase that was associated with the semantic unit, the item was scored as being 'understood' even if grammatically inaccurate as this did not indicate a failure to comprehend the text. The number of subjects reporting each semantic unit was then recorded by groups (see the appendix for a detailed breakdown). A total of the semantic units reported under each condition was then calculated and expressed as a percentage of all possible semantic units (35 x 10 for each condition).

\section{Results}

\subsection{Multimodality as an aid to comprehension}

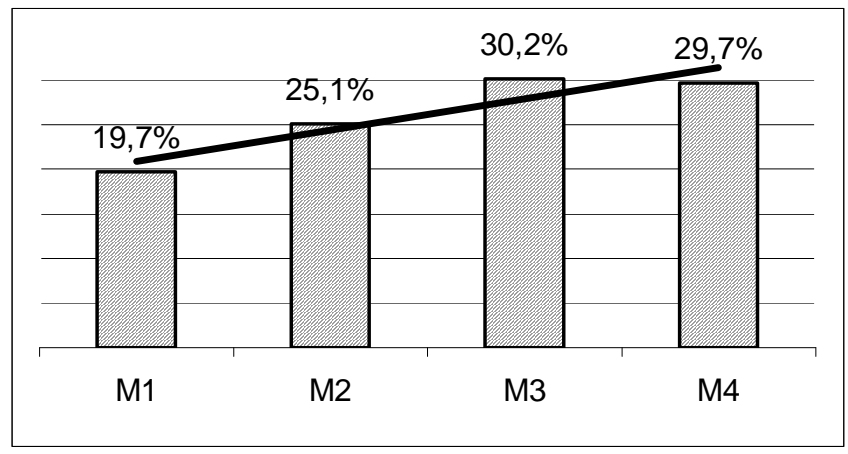

Figure 1: Percentage of possible semantic units reported by modalities

Figure 1 summarises the results. We can see that on average the ten M1 subjects (audio alone) made reference to $19.7 \%$ of the possible semantic units in their written summary. There is an increase for the M2 condition, where approximately one quarter of the possible items $(25.1 \%)$ were reported by subjects who had access to visual input. However, scores are higher still (approximately 30\%) with the subtitled versions, with no observably significant difference between those provided with subtitles in English (M3) and those provided with them in French (M4). Statistical indications of probability were not sought given the small size of the sample.

\subsection{Benefits and limitations of images}

It is interesting to compare the effects of the different channels upon what was reported. Precise identification of the main protagonists and settings in the source document was considerably affected by whether or not subjects had access to visual input. For instance, very few students in Condition M1 identified the Franco-American couple (items 3 and 4) and, without access to the images, no subject in this group was able to situate the place of work (item 23), whereas these key elements were identified by the subjects exposed to the other modalities (see appendix). 
However, images with or without subtitles, did not necessarily facilitate comprehension. This was shown to be the case for one of the key arguments in the source document, i.e. that Americans work more than their European counterparts and see their children less (see items 15, 16 and 20 in appendix). The reason could be that the key argument is delivered by the journalist in voice-over whilst the video shows short scenes of the couple going to work by car and driving past a succession of Washington city monuments. Here the information provided by the images is no longer supplementary as it is in the remainder of the report and students are faced with visual information which is not directly linked to the auditory information.

\subsection{Benefits and limitations of subtitles}

Subtitles appear to be a determining factor for understanding some of the information as shown in the case of two of the semantic units. The "three-year old" son chunk (item 6) posed comprehension problems in Condition M1, perhaps due to the typically English adjectival construction, but images supported by text seemed to enable subjects to confirm their understanding of this component. The example of the young au pair girl who looks after the couple's son is also of interest. Even though the lexical unit "au pair" appears in French in the report, not one student in the M1 group was able to identify this character, whereas the more explicit and well supported the input was, the higher the level of understanding (see items 6 and 14 in appendix).

\section{4. $L 1$ interference}

Although there is apparently no significant difference between the levels of understanding achieved with subtitles in L1 or in L2, it was clear that translating back into the students' L1 led to specific mistakes. One such error triggered by the French subtitles concerned the compound adjective "self-employed" (item 25), referring to the couple in the BBC report. In the French subtitled version (M4), this compound adjective was translated as "indépendant", the equivalent French term. In the written summaries of the five subjects who correctly understood this fact, we find: *The parents have an independent work in the salon (M4, S.1), They are independent workers (M4, S.3); *It is independant shop (M4, S.4); *They are independant (M4, S.5); * They have independant works $(M 4, S .6)$. It seems quite evident that interference between French and English impaired lexical accuracy as students concentrated on L1 subtitles rather than on the oral message in L2. M4 learners' note-taking also seems to be affected by the French subtitles as can be seen in an M4 subject's rough copy (video + French 
subtitles), where numerous Gallicisms are present such as "propriety" for owners (propriétaires), “journey” for day (journée) or "vacancy” for holiday (vacances).

\section{Discussion}

Given the limited number of participants, we have to emphasize that this pilot study can only allow us to draw tentative comparisons between the groups. These indicative results nevertheless conform with Baltova's finding (1999), obtained in similar experimental conditions, that associating images in L2 and text in L2, is an effective way of enhancing L2 learners' comprehension of authentic texts. Our choice of methodology allowed us to go further than Baltova in that the data elicited by asking learners to take notes and write a summary gave us access to parts of the process of comprehension, such as accuracy of lexical recognition, that remain invisible when subjects are merely asked to fill in a multiple choice questionnaire. The latter method would not have shown up such phenomena as the L1 to L2 transfer.

Effective L2 text comprehension requires learners to engage in a dynamic process which involves forming and testing hypotheses in real time with the support of preexisting knowledge (Caron, 1989). Images providing contextual clues would seem to strengthen this process as shown by the different levels of reporting in Conditions M1 and M2. However, this study also provides evidence that when visual information is not directly related to the oral message (e.g. Washington sights that are unconnected to the journalist's oral comments), there appears to be a cognitive overload. We therefore suggest that visual information which is not directly linked to the auditory information may distract learners' attention and create a split-attention effect, whereby exposure to simultaneous but different information carries a cognitive cost which is sometimes too high for students to process (Moreno and Mayer, 1999).

This study also enabled us to see that subtitling serves to make some parts of discourse less ambiguous. Whether in L1 or L2, subtitles appear to assist learners in decoding what is said and provide important propositional information. Yet three elements need to be emphasized. First, word meanings may be transparent when written but more difficult to recognise when presented orally, as is exemplified through the "au pair" item. Secondly, the study has shown that the choice of language influences the lexical accuracy of what is reported afterwards. Though students understood the same number of semantic units in both languages, the selection of appropriate lexis was better with L2 subtitles. Thirdly, subtitles set up a potential divided attention effect as written words are usually easier for learners to process than spoken. Thus they can prove to be a 
distraction in that they load on to reading skills and use a cue that would not be present in a real-life situation.

This raises the question of the compromise that needs to be found when designing a computer-mediated language learning resource for students. When choosing a video for pedagogical use, criteria such as speech rates, length, registers and number of speakers must be considered, as well as whether or not the image corresponds to the oral message. However, the most important consideration may be that redundancy of information helps text comprehension, so that learners should be exposed where possible to input that is multimodal, thus restoring some ecological validity to the learning experience and teaching them to exploit the potential of each medium.

Additional non-ecological assistance from subtitles can be usefully offered to learners when they have to process a complex video document. Nonetheless, the choice of whether to use subtitles should ultimately belong to the learner so that the acquisition of his/her listening skill can be accomplished strategically taking due account of the level of difficulty of the document, the aim of the listening task and the objectives that are pursued by each individual (see Pujolá, 2002; Borrás and Lafayette 1994).

Finally, we have demonstrated the potential of integrating an analysis of learners' understanding into the design of learning resources. It is an effective means of obtaining relevant information which serves to guide decision making regarding the optimum format and the choice of input and learning aids. In this way, resource development will be fully informed by empirical knowledge rather than intuition alone, which is clearly to the advantage of teachers and materials designers alike.

Nicolas Guichon is a lecturer at Lyon 2 University. His research focuses on teacher education, computer assisted language learning and materials design.

nicolas.guichon@univ-lyon2.fr

Sinead McLornan is a teacher of business English at the European Business Institute and is especially interested in research regarding ESL teaching. sineadmclornan@hotmail.com 


\section{Appendix 1}

\begin{tabular}{|c|c|c|c|c|}
\hline Modality (* see key below) & $\Sigma M 1$ & EM2 & EM3 & $\Sigma \mathrm{M} 4$ \\
\hline 1. Washington & 4 & 8 & 4 & 6 \\
\hline 2. Suburb & 1 & 2 & 2 & 1 \\
\hline 3. French man (Philippe Depeyrot) & 2 & 9 & 6 & 9 \\
\hline 4. American woman (Krista) & 3 & 9 & 6 & 8 \\
\hline 5. 30/about 30 & 0 & 0 & 1 & 0 \\
\hline 6. three-year old son & 2 & 5 & 7 & 10 \\
\hline 7. $\$ 3,000$ mortgage every month & 0 & 0 & 1 & 0 \\
\hline 8. full-time careers & 3 & 0 & 2 & 0 \\
\hline 9. $\mathrm{K}$ is pregnant & 2 & 3 & 5 & 4 \\
\hline 10. restructure lives to be a stay-at-home mom & 0 & 0 & 0 & 0 \\
\hline $11.1^{\text {st }}$ child = continue to work & 3 & 2 & 2 & 1 \\
\hline 12. $2^{\text {nd }}$ child $=$ the same & 0 & 0 & 1 & 1 \\
\hline 13. working week little quality time & 5 & 3 & 0 & 1 \\
\hline 14. Au pair in charge of the son (Julian) & 0 & 3 & 7 & 9 \\
\hline 15. Americans are working more & 6 & 0 & 3 & 1 \\
\hline 16. Seeing less of their children & 8 & 0 & 4 & 1 \\
\hline 17. $40 \%$ less than 40 years ago & 0 & 0 & 0 & 0 \\
\hline 18. Little annual leave & 0 & 3 & 1 & 4 \\
\hline 19. Americans work 2 months longer & 4 & 4 & 4 & 2 \\
\hline 20. than their European counterparts & 7 & 0 & 4 & 2 \\
\hline 21. Ph. Doesn't think Americans work harder & 2 & 3 & 3 & 1 \\
\hline 22. P \& K work together & 4 & 7 & 8 & 4 \\
\hline 23. exclusive hair salon & 0 & 9 & 9 & 9 \\
\hline 24. She earns twice as much & 1 & 0 & 2 & 2 \\
\hline 25. self-employed & 0 & 2 & 1 & 5 \\
\hline 26. few benefits (paid sick/maternity leave) & 0 & 1 & 1 & 4 \\
\hline 27. back to work 5 weeks after giving birth & 4 & 6 & 3 & 4 \\
\hline 28. a personal choice & 1 & 1 & 4 & 3 \\
\hline 29.3 months unpaid & 0 & 0 & 2 & 0 \\
\hline 30. P's surgery and the heavy burden & 0 & 0 & 0 & 1 \\
\hline 31. watching the play recorded by the au pair & 1 & 2 & 2 & 2 \\
\hline 32. couldn't see the play & 1 & 1 & 2 & 2 \\
\hline 33. would do differently if he could & 1 & 3 & 0 & 2 \\
\hline 34. only a few hours together & 0 & 0 & 0 & 0 \\
\hline 35. traditional US life & 4 & 2 & 9 & 5 \\
\hline$\Sigma$ & 69 & 88 & 106 & 104 \\
\hline$\%$ & 19.7 & 25.1 & 30.2 & 29.7 \\
\hline
\end{tabular}

* key:

M1: audio alone

M2: audio \& images

M3: audio \& images \& English subtitles

M4: audio \& images \& French subtitles 


\section{References}

Baltova, I., 1999. Multisensory Language Teaching in a Multidimensional Curriculum: The Use of Authentic Bimodal Video in Core French. Canadian Modern Language Review 56 (1), 32-48.

Borras, I., Lafayette, R., 1994. Effects of multimedia courseware subtitling on the speaking performance of college students of French. The Modern Language Journal 78 (1), 61-75.

Brown, G., Yule, G., 1983. Discourse Analysis. Cambridge University Press, Cambridge.

Caron, J., 1989. Précis de psycholinguistique. PUF, Paris.

Chapelle, C.A., 2003. English Language Learning and Technology. John Benjamins, Amsterdam.

Kon, C.K., 2002. The influence on outcomes of ESL students' performance strategies on a CALL listening comprehension activity. Unpublished MA thesis, Department of English, Iowa State University, Ames, IA, USA.

Kress, G., Van Leeuwen, T., 1996. Reading Images: The Grammar of Visual Design. Routledge, New York.

Legros, D., Crinon, J., (Eds.) 2002. Psychologie des apprentissages et multimedia. Armand Colin, Paris.

Moreno, R., Mayer, R., 1999. Cognitive principles of multimedia learning: the role of modality and contiguity. Journal of Educational Psychology 91, 358-368.

Pujolá, J.-T., 2002. CALLing for help: Researching language learning strategies using help facilities in a web-based multimedia program. ReCALL 14 (2), 235-262.

Rost, M., 2002. Teaching and Researching Listening. Longman, London.

Schnotz, W., 1999. Introduction. European Journal of Psychology of Education XIV (2), 163-165.

Tardieu, H., Gyselinck, V., 2003. Working memory constraints in the Integration and Comprehension of Information in a Multimedia Context. In: van Oostendorp, H. (Ed.).

Cognition in a digital world. Lawrence Erlbaum, London. pp. 3-24

Wickens, C.D., 1984. Engineering psychology and human performance. Merrill Publishing, Columbus.

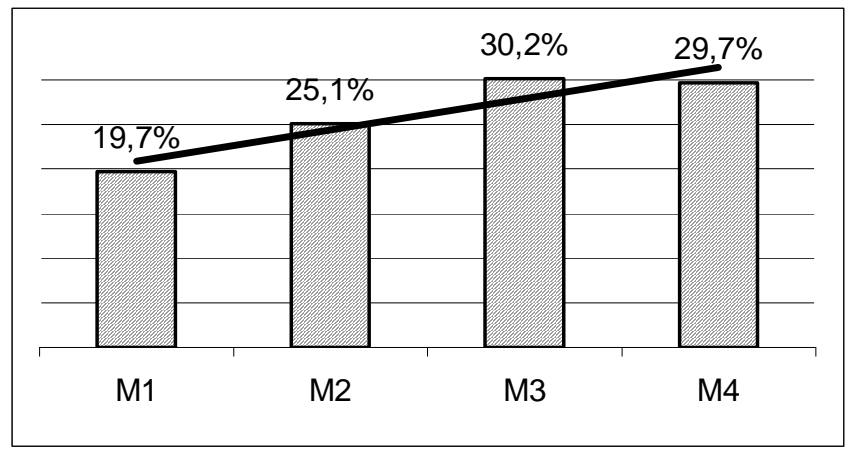

Figure 2:

Percentage of possible semantic units reported by modalities 